\title{
Avaliação da percepção de satisfação do sorriso e da influência das mídias sociais digitais na população
}

\author{
Evaluation of the perception of smile satisfaction and the influence of digital social media on the \\ population
}

Evaluación de la percepción de satisfacción por sonrisa y la influencia de las redes sociales digitales en la población

\section{Resumo}

Introdução: A crescente participação das mídias sociais no cotidiano da população vem moldando a forma como as pessoas percebem a si mesmas. A satisfação com a própria imagem é construída pela mescla de fatores intrínsecos ao próprio ser e às influências do meio externo, e agora, pelas redes sociais. Como o brasileiro consome muito as mídias sociais digitais, essa presença exagerada "impõe" novos parâmetros de beleza. Objetivo: Avaliar a percepção de satisfação do sorriso sob influência das mídias sociais digitais na população. Material e método: Estudo transversal descritivo, abordagem quali-quatitativa, com aplicação de questionário online no formato Google Docs, enviado de forma aleatória aos participantes por meio de redes sociais. Os dados obtidos foram transpostos para o programa Excel e analisados através das frequências das variáveis. Resultados: Responderam ao formulário 171 pessoas. O perfil socioeconômico compõe majoritariamente mulheres $(76 \%)$, residentes na região Nordeste do Brasil $(96,5 \%)$, ensino superior incompleto (33,3\%), faixa etária de 25 a 31 anos $(48 \%)$, renda familiar mensal de 3 a 5 salários mínimos $(36,8 \%)$ e que utilizam as redes sociais digitais WhatsApp e Instagram em sua maioria, por mais de 4 horas diárias (62\%). A posição dos dentes foi a característica mais importante do sorriso para 83,6\% (n=143) dos entrevistados; $62 \%$ (106) gostariam de realizar alguma mudança no próprio sorriso e quase metade dos entrevistados $(47,4 \%, n=80)$ consideram que as mídias sociais digitais influenciam parcialmente nas respostas atribuídas ao questionário. Conclusão: Os entrevistados afirmaram que estão felizes com seus sorrisos, mas ainda desejam modificar algo. A percepção do sorriso, de um modo geral, é influenciada pela vivência dos entrevistados nas mídias sociais digitais.

Palavras-chave: Beleza; Mídias sociais; Satisfação Pessoal; Sorriso.

\section{Abstract}

Introduction: The increasing participation of social media in the daily lives of the population has been shaping the way people perceive themselves. Satisfaction with one's own image is built by a mixture of factors intrinsic to one's 
being and the influences of the external environment, and now, by digital social media. As the Brazilian consumes a lot of digital social media, this exaggerated presence "imposes" new parameters of beauty. Objective: Evaluate the perception of smile satisfaction under the influence of digital social media in the population. Material and method: Descriptive cross-sectional study, qualitative and quantitative approach, with the application of an online questionnaire in the Google Docs format, sent at random to participants through social networks. Results: 171 people responded. The socioeconomic profile mainly comprises women (76\%), living in the Northeast region of Brazil $(96,5 \%)$, incomplete higher education (33,3\%), age group 25 to 31 years old (48\%), monthly family income of 3 to 5 minimum wages $(36,8 \%)$, mostly using the digital social networks WhatsApp and Instagram, for more $4 \mathrm{~h}$ daily $(62 \%)$. The position of the teeth was the most important characteristic of the smile for $83.6 \%(\mathrm{n}=143)$ of the interviewees; $62 \%$ (106) would like to make some change in their smile and almost half of the interviewees $(47.4 \%, \mathrm{n}$ $=80$ ) consider that digital social media partially influence the responses attributed to the questionnaire. Conclusion: Respondents stated that they are happy with their smiles, but still want to change something. The perception of the smile, in general, is influenced by the interviewees' experience in digital social media.

Keywords: Beauty; Social media; Personal satisfaction; Smile.

\section{Resumen}

Introducción: La creciente participación de las redes sociales en la vida diaria de la población ha ido moldeando la forma en que las personas se perciben a sí mismas. La satisfacción con la propia imagen se construye mediante una mezcla de factores intrínsecos al propio ser y las influencias del entorno externo, y ahora, por las redes sociales digitales. Como el brasileño consume una gran cantidad de redes sociales digitales, esta presencia exagerada "impone" nuevos parámetros de belleza. Objetivo: Evaluar la percepción de satisfacción de la sonrisa bajo la influencia de las redes sociales digitales en la población. Material y método: Estudio descriptivo transversal, abordaje cualitativo y cuantitativo, con la aplicación de un cuestionario online en formato Google Docs, enviado de forma aleatoria a los participantes a través de las redes sociales. Resultados: 171 encuestados respondieron. El perfil socioeconómico comprende principalmente mujeres (76\%), residentes en la región Nordeste de Brasil (96,5\%), educación superior incompleta (33,3\%), grupo de edad de 25 a 31 años (48\%), ingresos familiares mensuales de 3 a 5 salarios mínimos (36,8\%), mayoritariamente utilizando las redes sociales digitales WhatsApp e Instagram, para más 4 horas diarias (62\%). La posición de los dientes fue la característica más importante de la sonrisa para el 83,6\% $(\mathrm{n}=$ 143) de los entrevistados; El 62\% (106) quisiera hacer algún cambio en su sonrisa y casi la mitad de los entrevistados $(47,4 \%, n=80)$ considera que las redes sociales digitales influyen parcialmente en las respuestas atribuidas al cuestionario. Conclusión: Los encuestados afirmaron que están contentos con sus sonrisas, pero que aún quieren cambiar algo. La percepción de la sonrisa, en general, está influenciada por la experiencia de los entrevistados en las redes sociales digitales.

Palabras clave: Belleza; Redes sociales; Satisfacción personal; Sonreí.

\section{Introdução}

O avanço tecnológico, experimentado nessa $2^{a}$ década do século XXI, tem demonstrado como as relações sociais e o consumo são diretamente influenciados pelo acesso facilitado à informação. O brasileiro tem aceitado bem a troca gradativa dos meios de comunicação comuns (jornais, televisão, rádio) para receber todo tipo de informação pelo smartphone. Os jovens são os que mais consomem informação pelo celular, afinal, já nasceram e cresceram acompanhando a evolução tecnológica (Macedo, 2016).

Desde a criação da internet no fim dos anos 1960 e sua popularização no Brasil no fim dos anos 1990, a sociedade tem experimentado uma transformação nas formas de acesso às informações, bem como a forma de compartilhá-las (Lins, 2013). Dessa forma, muitos são consumidores da informação recebida pela internet e replicadores dessa informação (Hung e Yuen, 2010; Macedo, 2016).

No âmbito das relações interpessoais, o termo "rede social" é referenciado como uma relação entre grupo de pessoas, podendo ser físico ou através da internet ou outro meio. Nesse conceito, os indivíduos participantes trocam experiências, argumentam entre si, compartilham informações. Tais interações, ocorrem em espaços onde os indivíduos se fazem presentes, tanto fisicamente (ambiente familiar, local de trabalho, sala de reuniões, igreja), quanto compartilhando virtualmente, através do uso da internet (Recuero, 2014).

Os usuários de redes sociais digitais compartilham informações e experiência por intermédio de um site ou aplicativo.

Segundo Recuero (2014), a internet facilitou que o maior número de pessoas tenha acesso às redes sociais em seu uso 
cotidiano, tendo a comunicação entre um maior número de pessoas fora do seu círculo social diário mais aberto, podendo alcançar pessoas de todos os cantos do mundo (Lima, 2017).

Com a popularização das redes sociais, uma nova categoria foi adicionada ao dicionário tecnológico: mídias sociais. De acordo com Rocha Neto (2015) “Mídias sociais quer dizer 'permitir conversações'. Elas são sites na internet construídos para permitir interação social e o compartilhamento de informações em vários formatos: fotos, mensagens, ícones, entre outros".

Mesmo os estudos históricos mais antigos mostraram como os seres humanos consideravam diferenciar o feio do belo, onde a feiura era caracterizada como deformidade, e a beleza como simetria e harmonia. Essas duas definições sempre passaram e continuam passando por modificações minuciosas era após era, onde fatores sociais, culturais, religiões, sistemas econômicos, e hoje em dia, as mídias sociais, agem transformando seu sentido (Barros, 2017; Kury, Hangreaves, Valença, 2000 apud Suenaga et al., 2012).

A forma como percebemos nosso próprio corpo e a forma como queremos transmitir características da nossa personalidade, gostos e emoções resultam no que chamamos de imagem corporal. Essa imagem de si, que é apresentada aos outros, é altamente influenciada pelas mídias, que sempre ressaltam valores estéticos perfeitos (e irreais), convergindo para um padrão único (Vargas, 2014).

A percepção da imagem corporal pode ser considerada, muitas vezes, como resultado de distorções da própria imagem entendidas pelo indivíduo com um conflito entre o corpo real e o imposto pela sociedade (Zenith et al 2012 apud Vargas 2014).

Pelo fato das pessoas estarem constantemente acessando as mídias sociais, a sua atuação na autopercepção da beleza e seu impacto na forma como as pessoas se veem, vem sendo pesquisada cada vez mais (Vermelho et al., 2015; Fardouly et al., 2015; Tiggermann et al., 2016). Assim, pelo uso contínuo da internet e das mídias sociais, as pessoas são mais expostas à propaganda exacerbada, repetitiva e contínua, influenciando como as pessoas consomem produtos e serviços (Macedo 2016).

A mídia, independente da época ou dos meios de propagação, sempre influenciou a sociedade de várias maneiras, diversos segmentos da vida, ditando comportamentos e desejos. Pela inserção da internet no nosso cotidiano, essa "mídia massiva" está incorporando no nosso dia a dia mudanças significativas na nossa cultura, manipulando e/ou motivando os seres humanos a conhecerem assuntos dos mais diversos tipos, induzindo o consumo e modificando costumes (Silva, 2019).

Nesse sentido, os influenciadores digitais conquistam cada vez mais espaço e evidência, expondo seus hábitos diários, preferências, maneira de se vestir e hobbies, objetivando engajamento e aproximação com o seu público alvo. O público que se espelha nessas personalidades digitais, articulam maneiras de estar cada vez mais semelhantes com elas, principalmente na aparência corporal. Diante disso, os conteúdos postados nas redes sociais propiciam ao indivíduo a construção da imagem de si que ele deseja transmitir para os outros, com características que se formam a partir dos estereótipos que predominam em seu meio social (Carrera, 2012; Vieira, 2019).

De acordo com Gimenez (2016), as pessoas percebem a beleza como um conjunto de atributos que despertam interesse ao ser visto, que aguçam os sentidos, traz prazer à mente. Logo, quanto mais se vê publicações e publicidades com sorrisos perfeitos, extremamente brancos, dentes alinhados, e pelo mecanismo que as mídias sociais digitais tendem a replicar o mesmo conteúdo exaustivas vezes; o público, que foi atraído pelo excesso de informação, parte para o pressuposto que tudo que é visto é o "normal", e passa a aceitar aquilo como padrão. Logo, o sorriso extremamente branco torna-se uma "falsa realidade", porém vivenciada nas mídias sociais digitais diariamente.

Atualmente, os pacientes procuram o consultório odontológico para além da saúde bucal; eles procuram cada vez mais pela estética facial e bucal. A popularização de procedimentos como a harmonização facial é uma aliada na busca de um sorriso harmônico e simétrico, que é associado à jovialidade (Cavalcanti, 2017). 
E para atender à crescente demanda da procura por um sorriso perfeito digno de comercial de pasta de dente, os pacientes cada vez mais recorrem às lentes de contato dentais, "que se constituem de laminados de cerâmicas de espessura ultrafina cimentados ao esmalte dental por técnicas de cimentação adesiva em dentes anteriores” (Ribeiro, 2015).

Dessa forma, o objetivo do presente trabalho é avaliar a percepção de satisfação do sorriso e da influência das mídias sociais digitais na população, com o intuito de entender como essas mídias sociais influenciam no poder de percepção da autoimagem do paciente.

\section{Metodologia}

\subsection{Tipo de Estudo}

O presente trabalho foi aprovado pelo Comitê de Ética em Pesquisa do Hospital Universitário Alcides Carneiro da Universidade Federal de Campina Grande / HUAC - UFCG, sob parecer n ${ }^{\circ}$ 4.418.306.

Tratou-se de um estudo transversal descritivo, de abordagem quali-quantitativa, com aplicação de questionário online no formato Google Docs. O acesso ao questionário ocorreu pelo envio do link do mesmo via mídias sociais digitais WhatsApp, Instagram, Twitter e Facebook.

\subsection{Critérios de inclusão e exclusão}

Participaram da pesquisa as pessoas que receberam o link, responderam corretamente os questionários e que consentiram a participação na pesquisa por meio da assinatura do Termo de Consentimento Livre e esclarecido (TCLE). Foram excluídos da pesquisa as pessoas que não enviarem o formulário dentro do prazo estabelecido pela pesquisadora

\subsection{Elaboração e aplicação do questionário}

O questionário foi enviado através das mídias sociais digitais da entrevistadora, para toda sua lista de contatos, e solicitado que os remetentes as encaminhassem para seus respectivos contatos, dessa forma aumentando o alcance do questionário. A população do estudo compreendeu todas as pessoas que tiveram acesso ao link do questionário no período de janeiro a junho de 2020. O link contendo a pesquisa foi divulgado através das redes sociais WhatsApp, Twitter, Instagram e Facebook com o objetivo de atingir diferentes grupos populacionais.

Utilizando como base o questionário utilizado por Silva (2018), foi criado o questionário online intitulado “Avaliação da percepção de satisfação do sorriso e da influência das mídias sociais digitais na população" foi criado pelo site Google Docs (Google Inc., USA).

O questionário para coleta dos dados foi submetido inicialmente a dois pré-testes para ser avaliado, recebendo adequações e esclarecimentos adicionais quanto ao seu preenchimento. Para os pré-testes foram selecionados aleatoriamente dez pessoas pertencentes à população-alvo, os quais não tiveram seus dados aproveitados na pesquisa. Os pré-testes tiveram a finalidade de aperfeiçoar o instrumento de coleta de dados. Foram objetivos dos pré-testes verificar se as questões estavam claras, diretas e se a sequência das questões era adequada (Marconi e Lakatos, 2010). Após a revisão do questionário, este foi devidamente formatado para envio aos participantes.

A primeira parte do questionário continha o Termo de Consentimento Livre e Esclarecido (questão 2), para o entrevistado ler em anexo e decidir se participaria da pesquisa. A validação da resposta do entrevistado só existiu quando é assinalado a resposta “Concordo em Responder”. Caso contrário, as respostas não seriam contabilizadas na apuração final.

A segunda parte do questionário, das questões 3 a 7, foram relacionadas ao perfil dos entrevistados: sexo, região onde reside, escolaridade, faixa etária e renda. A questão 8 visou saber quais redes sociais os entrevistados mais utilizavam. Por existirem várias redes sociais com diversas finalidades, a questão foi de múltipla escolha com várias respostas possíveis, onde 
o entrevistado pode assinalar todas, várias ou nenhuma. A questão 9 constituiu interesse em saber quanto tempo os entrevistados despendem acessando as mídias sociais.

A terceira parte do questionário englobou questões sobre características do sorriso. Das questões 10 a 15 , foi perguntado sobre diferentes características do sorriso, sua satisfação com o próprio sorriso, se mudaria algo e o quê mudaria. A questão 16 representa o nível de consciência do entrevistado diante da influência das mídias sociais em sua percepção com a satisfação do sorriso. Será que o ideal de sorriso que o entrevistado tem em mente, é fruto inteiramente do que ele vivencia nas mídias sociais?

A questão 17, de resposta aberta, solicitou-se que o entrevistado sugerisse o nome de alguma pessoa conhecida popularmente. As respostas dessa questão foram variadas, pois elas podem ser influenciadas por todas as mídias (sociais ou não), como TV aberta, TV por assinatura, jornais, revistas, e redes sociais no geral.

E por fim, da questão 18 a 26, foi apresentado ao entrevistado várias perguntas com diversas fotos do sorriso de pessoas influentes de redes sociais, questionando o entrevistado a avaliar o sorriso da pessoa em questão como "menos atrativo" ou "mais atrativo" numa escala de 1 a 10 respectivamente. Foram escolhidas imagens de influenciadores preferencialmente mais conhecidos nas mídias sociais digitais e foram utilizadas imagens onde pode se ver somente o terço inferior da face em todas elas, tendo o resto da face cortado para não estimular respostas positivas ou negativas na nota atribuída aos sorrisos. As fotos foram selecionadas de maneira que a face, os lábios e os dentes pudessem ser visualizados com clareza, contendo cada fotografia uma característica diferente (Tabela 1).

Tabela 1. Características das imagens utilizadas no questionário.

\begin{tabular}{|c|c|}
\hline IMAGEM & Característica \\
\hline $\begin{array}{l}18 \text { Chata de Galocha (Luíza } \\
\text { Ferreira) }\end{array}$ & $\begin{array}{l}\text { Posição da cabeça em vista frontal. Sorriso com dentes muito claros e alinhados, tamanho de dentes } \\
\text { compridos e largos, lábios superior e inferior de tamanhos simétricos }\end{array}$ \\
\hline $\begin{array}{l}19 \text { Gabbie Fadel (Gabriela } \\
\text { Fadel) }\end{array}$ & $\begin{array}{l}\text { Posição da cabeça em vista parcialmente lateralizada. Sorriso com dentes claros e alinhados, com } \\
\text { leve overjet, tamanho de dentes pequenos e largos, lábio inferior mais evidente que lábio superior }\end{array}$ \\
\hline 20 Camila Coutinho & $\begin{array}{l}\text { Posição da cabeça em vista frontal. Sorriso com dentes claros e alinhados, tamanho de dentes } \\
\text { compridos e largos, lado direito do lábio superior mais elevado que seu lado esquerdo; lábio inferior } \\
\text { mais evidente que lábio superior }\end{array}$ \\
\hline 21 Julia Petit & $\begin{array}{l}\text { Posição da cabeça em vista látero-inferior. Sorriso com dentes muito claros e alinhados, nenhuma } \\
\text { gengiva à mostra, tamanho de dentes largos, lábio superior com preenchimento na altura dos } \\
\text { caninos. Lábio superior e inferior de tamanhos equivalentes }\end{array}$ \\
\hline $\begin{array}{l}22 \text { Niina Secrets (Bruna } \\
\text { Santina) }\end{array}$ & $\begin{array}{l}\text { Posição da cabeça em vista parcialmente lateralizada. Sorriso com dentes muito claros e alinhados, } \\
\text { tamanho de dentes finos, lado direito do lábio superior mais elevado que seu lado esquerdo; lábio } \\
\text { inferior mais evidente que lábio superior }\end{array}$ \\
\hline $\begin{array}{l}23 \text { Simply Nailogical } \\
\text { (Cristine Raquel Rotenberg) }\end{array}$ & $\begin{array}{l}\text { Posição da cabeça em vista parcialmente lateralizada. Sorriso com dentes claros e alinhados, alguns } \\
\text { dentes largos e outros finos, lábio inferior muito mais evidente que lábio superior }\end{array}$ \\
\hline 24 Whinderson Nunes & $\begin{array}{l}\text { Posição da cabeça em vista lateral. Sorriso com dentes muito claros e alinhados, tamanho de dentes } \\
\text { largos e curtos, lábio inferior ligeiramente mais evidente que lábio superior }\end{array}$ \\
\hline $\begin{array}{l}25 \text { Boca Rosa (Bianca } \\
\text { Andrade) }\end{array}$ & $\begin{array}{l}\text { Posição da cabeça em vista frontal. Sorriso com dentes claros e alinhados, desproporção entre } \\
\text { incisivos centrais e laterais superiores, tamanho de dentes pequenos e estreitos, lábio superior } \\
\text { ligeiramente mais fino que lábio inferior }\end{array}$ \\
\hline 26 Renata Meins & $\begin{array}{l}\text { Posição da cabeça em vista frontal. Sorriso com dentes claros e alinhados, com overjet, grande } \\
\text { exposição de gengiva superior, tamanho dos dentes pequenos e largos, lábio superior e inferior de } \\
\text { tamanhos simétricos }\end{array}$ \\
\hline
\end{tabular}




\subsection{Análise e interpretação de dados}

Todas as respostas obtidas foram computadas automaticamente pelo Google Docs, transformando-as em um arquivo .pdf e .xlsx, onde foi possível analisar estatisticamente cada pergunta e/ou resposta individual de cada entrevistado.

\section{Resultados}

\subsection{Caracterização da amostra:}

Responderam ao questionário 171 pessoas. Os dados relacionados ao perfil dos entrevistados encontram-se expostos na Tabela 2.

Tabela 2. Perfil dos entrevistados. Patos, PB, 2020.

\begin{tabular}{|c|c|c|}
\hline Perfil dos entrevistados & $\mathbf{n}$ & $\%$ \\
\hline \multicolumn{3}{|l|}{ Sexo } \\
\hline Masculino & 41 & $24 \%$ \\
\hline $\begin{array}{l}\text { Feminino } \\
\text { Região em que reside }\end{array}$ & 130 & $76 \%$ \\
\hline $\begin{array}{l}\text { Nordeste } \\
\text { Sul } \\
\text { Sudeste } \\
\text { Centro-oeste }\end{array}$ & $\begin{array}{c}165 \\
3 \\
2 \\
1\end{array}$ & $\begin{array}{c}\mathbf{9 6 , 5 \%} \\
1,8 \% \\
1,2 \% \\
0,6 \%\end{array}$ \\
\hline $\begin{array}{l}\text { Escolaridade } \\
\text { Ensino fundamental incompleto } \\
\text { Ensino fundamental completo } \\
\text { Ensino Médio } \\
\text { Ensino Superior Incompleto } \\
\text { Ensino Superior Completo } \\
\text { Pós-graduação Incompleta } \\
\text { Pós-graduação Completo }\end{array}$ & $\begin{array}{c}1 \\
1 \\
5 \\
57 \\
55 \\
25 \\
27\end{array}$ & $\begin{array}{c}0,6 \% \\
0,6 \% \\
2,9 \% \\
\mathbf{3 3 , 3 \%} \\
32,2 \% \\
14,6 \% \\
15,8 \%\end{array}$ \\
\hline $\begin{array}{l}\text { Faixa etária } \\
18 \text { a } 24 \text { anos } \\
25 \text { a } 31 \text { anos } \\
32 \text { a } 38 \text { anos } \\
39 \text { a } 45 \text { anos }\end{array}$ & $\begin{array}{c}62 \\
82 \\
18 \\
5\end{array}$ & $\begin{array}{l}36,3 \% \\
\mathbf{4 8 \%} \\
10,5 \% \\
2,9 \%\end{array}$ \\
\hline $\begin{array}{l}\text { Renda mensal familiar } \\
\text { Até } 1 \text { salário mínimo } \\
1-3 \text { salários } \\
3-5 \text { salários } \\
6-9 \text { salários } \\
9-12 \text { salários } \\
12-15 \text { salários } \\
\text { Mais de } 15 \text { salários }\end{array}$ & $\begin{array}{c}9 \\
55 \\
63 \\
24 \\
9 \\
4 \\
7\end{array}$ & $\begin{array}{c}5,3 \% \\
32,2 \% \\
\mathbf{3 6 , 8 \%} \\
14 \% \\
5,3 \% \\
2,3 \% \\
4,1 \%\end{array}$ \\
\hline $\begin{array}{l}\text { Tempo diário de acesso às míd } \\
\text { Até } 1 \text { h por dia } \\
2 \text { a } 3 \text { horas por dia } \\
\text { Mais de } 4 \text { hs por dia }\end{array}$ & $\begin{array}{c}4 \\
61 \\
106\end{array}$ & $\begin{array}{c}2,3 \% \\
35,7 \% \\
\mathbf{6 2 \%}\end{array}$ \\
\hline $\begin{array}{l}\text { Mídia social digital mais utiliza } \\
\text { whatsapp } \\
\text { Instagram } \\
\text { Facebook } \\
\text { Twitter } \\
\text { Youtube } \\
\text { Pinterest } \\
\text { Tinder } \\
\text { Tiktok }\end{array}$ & $\begin{array}{c}167 \\
158 \\
52 \\
59 \\
98 \\
35 \\
9 \\
2 \\
\end{array}$ & $\begin{array}{c}97,7 \% \\
92,4 \% \\
30,4 \% \\
34,5 \% \\
57,3 \% \\
20,5 \% \\
5,3 \% \\
1,2 \% \\
\end{array}$ \\
\hline
\end{tabular}


Fonte: Autores.

\section{2 avaliação do sorriso}

A Tabela 3 apresenta os dados relacionados a avaliação geral do sorriso.

Tabela 3. Avaliação geral do sorriso. Patos-PB, 2020.

\begin{tabular}{|c|c|c|}
\hline Avaliação geral do sorriso & $\mathbf{n}$ & $\%$ \\
\hline \multicolumn{3}{|l|}{ Características mais atrativas do sorriso* } \\
\hline Posição dos dentes & 143 & $83,6 \%$ \\
\hline Cor dos dentes & 114 & $66,7 \%$ \\
\hline Tamanho dos dentes & 66 & $38,6 \%$ \\
\hline Formato da boca & 85 & $49,7 \%$ \\
\hline \multicolumn{3}{|l|}{ Satisfação com o próprio sorriso } \\
\hline Totalmente satisfeito & 30 & $17,5 \%$ \\
\hline Satisfeito, porém gostaria de alguma mudança & 106 & $62 \%$ \\
\hline Insatisfeito e gostaria de mudar & 34 & $19,9 \%$ \\
\hline Insatisfeito, porém não gostaria de mudar & 1 & $0,6 \%$ \\
\hline \multicolumn{3}{|l|}{ O que mudaria no seu sorriso* } \\
\hline A cor dos dentes & 89 & $52 \%$ \\
\hline A posição dos dentes & 65 & $38 \%$ \\
\hline O tamanho dos dentes & 32 & $18,7 \%$ \\
\hline A altura da gengiva & 19 & $11,1 \%$ \\
\hline O formato da boca & 18 & $10,5 \%$ \\
\hline Colocaria implante ou prótese em dentes ausentes & 11 & $6,4 \%$ \\
\hline Não mudaria nada & 27 & $15,8 \%$ \\
\hline \multicolumn{3}{|l|}{ O que considera mais atraente em relacão aos dentes } \\
\hline Dentes compridos e largos & 75 & $43,9 \%$ \\
\hline Dentes compridos e estreitos & 30 & $17,5 \%$ \\
\hline Dentes pequenos e largos & 26 & $15,2 \%$ \\
\hline Dentes pequenos e estreitos & 5 & $2,9 \%$ \\
\hline Nenhuma das características atrativas & 35 & $20,5 \%$ \\
\hline \multicolumn{3}{|l|}{ Posição dentária mais atraente } \\
\hline Dentes alinhados em seus arcos & 158 & $92,4 \%$ \\
\hline Dentes separados (diastema anterior) & 8 & $4,7 \%$ \\
\hline Dentes com leve apinhamento & 4 & $2,3 \%$ \\
\hline Dentes com diastema generalizado & 1 & $0,6 \%$ \\
\hline \multicolumn{3}{|l|}{ Em relação a cor dos dentes } \\
\hline Dente naturais claros & 109 & $63,75 \%$ \\
\hline Dentes naturais muito claros & 54 & $31,6 \%$ \\
\hline Dentes muito brancos & 8 & $4,7 \%$ \\
\hline
\end{tabular}

Fonte: Autores.

O Gráfico 1 apresenta o Nível de consciência dos entrevistados diante da influência das mídias sociais em sua percepção com a satisfação do sorriso. 
Gráfico 1. Nível de consciência dos entrevistados diante da influência das mídias sociais em sua percepção com a satisfação do sorriso. Patos-PB, 2020.

Sobre as respostas que você deu às perguntas anteriores, você considera que as mídias sociais (Instagram, Twitter, Facebook, WhatsApp) influenciaram sua escolha?

171 respostas
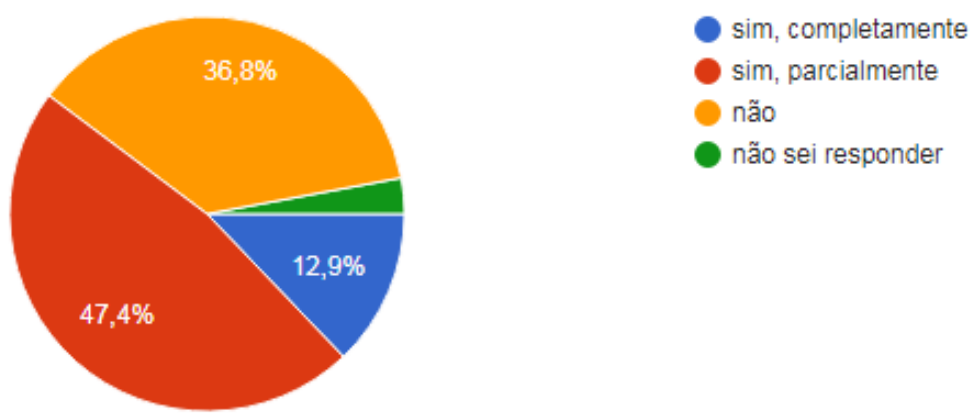

Fonte: Autores.

O Gráfico 2 apresenta as Pessoas popularmente conhecidas no país citadas pelos entrevistados como referencial de beleza relacionada ao sorriso.

Gráfico 2. Pessoas popularmente conhecidas no país citadas pelos entrevistados. Patos-PB, 2020.

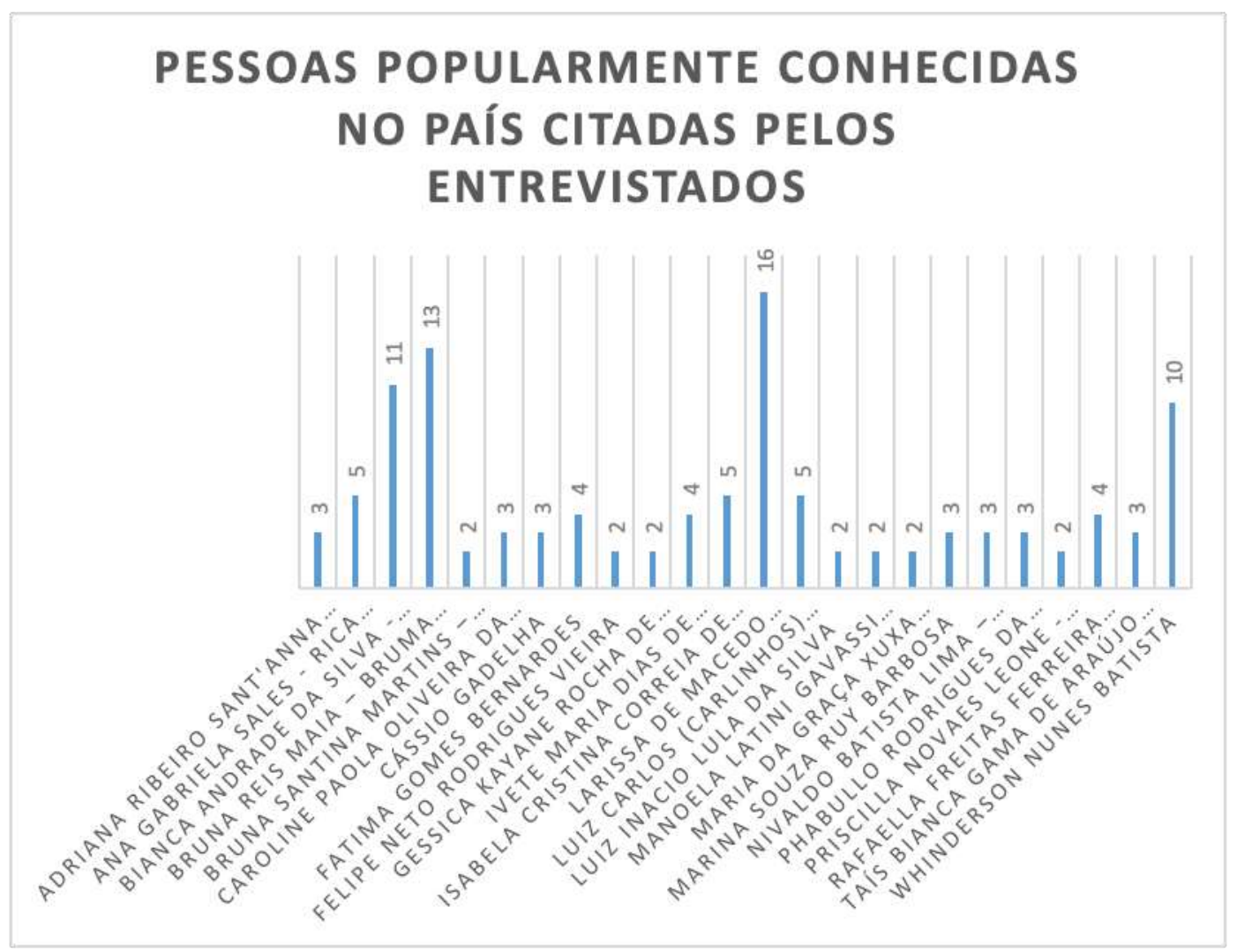

Fonte: Autores. 
A Tabela 4 apresenta as avaliações atribuídas pelos participantes as 9 imagens de sorriso apresentadas aos mesmos de forma aleatória e impessoal. Observa-se nas imagens de número 7, 6 e 9 foram as que apresentaram, respectivamente, as piores notas. A imagem 1 foi a que recebeu maiores percentuais de nota máxima, seguidas das imagens 3 e 4 .

Tabela 4. Notas atribuídas às imagens demonstradas no questionário. Patos-PB, 2020.

\begin{tabular}{|c|c|c|c|c|c|c|c|c|c|c|}
\hline \multirow[t]{2}{*}{ Imagens } & \multicolumn{10}{|c|}{ Notas Atribuídas } \\
\hline & 1 & 2 & 3 & 4 & 5 & 6 & 7 & 8 & 9 & 10 \\
\hline Imagem $n^{\circ} 1$ & $\begin{array}{c}0 \\
0 \%\end{array}$ & $\begin{array}{c}0 \\
0 \%\end{array}$ & $\begin{array}{c}1 \\
0,6 \%\end{array}$ & $\begin{array}{c}2 \\
1,2 \%\end{array}$ & $\begin{array}{c}13 \\
7,6 \%\end{array}$ & $\begin{array}{c}12 \\
7 \%\end{array}$ & $\begin{array}{c}26 \\
15,2 \%\end{array}$ & $\begin{array}{c}52 \\
30,4 \%\end{array}$ & $\begin{array}{c}42 \\
24,6 \%\end{array}$ & $\begin{array}{c}23 \\
13,5 \%\end{array}$ \\
\hline Imagem $n^{\circ} 2$ & $\begin{array}{c}0 \\
0 \%\end{array}$ & $\begin{array}{c}3 \\
1,8 \%\end{array}$ & $\begin{array}{c}9 \\
5,3 \%\end{array}$ & $\begin{array}{c}14 \\
8,2 \%\end{array}$ & $\begin{array}{c}16 \\
9,4 \%\end{array}$ & $\begin{array}{c}34 \\
19,9 \%\end{array}$ & $\begin{array}{c}44 \\
25,7 \%\end{array}$ & $\begin{array}{c}26 \\
15,2 \%\end{array}$ & $\begin{array}{c}15 \\
8,8 \%\end{array}$ & $\begin{array}{c}10 \\
5,8 \%\end{array}$ \\
\hline Imagem $n^{\circ} 3$ & $\begin{array}{c}2 \\
1,2 \%\end{array}$ & $\begin{array}{c}4 \\
2,3 \%\end{array}$ & $\begin{array}{c}4 \\
2,3 \%\end{array}$ & $\begin{array}{c}11 \\
6,4 \%\end{array}$ & $\begin{array}{c}15 \\
8,8 \%\end{array}$ & $\begin{array}{c}18 \\
10,5 \%\end{array}$ & $\begin{array}{c}35 \\
20,5 \%\end{array}$ & $\begin{array}{c}35 \\
20,5 \%\end{array}$ & $\begin{array}{c}28 \\
16,4 \%\end{array}$ & $\begin{array}{c}19 \\
11,1 \%\end{array}$ \\
\hline Imagem $n^{\circ} 4$ & $\begin{array}{c}4 \\
2,3 \%\end{array}$ & $\begin{array}{c}0 \\
0 \%\end{array}$ & $\begin{array}{c}10 \\
5,8 \%\end{array}$ & $\begin{array}{c}5 \\
2,9 \%\end{array}$ & $\begin{array}{c}30 \\
17,5 \%\end{array}$ & $\begin{array}{c}17 \\
9,9 \%\end{array}$ & $\begin{array}{c}31 \\
18,1 \%\end{array}$ & $\begin{array}{c}24 \\
14 \%\end{array}$ & $\begin{array}{c}35 \\
20,5 \%\end{array}$ & $\begin{array}{c}15 \\
8,8 \%\end{array}$ \\
\hline Imagem $n^{\circ} 5$ & $\begin{array}{c}3 \\
1,8 \%\end{array}$ & $\begin{array}{c}5 \\
2,9 \%\end{array}$ & $\begin{array}{c}16 \\
9,4 \%\end{array}$ & $\begin{array}{c}19 \\
11,1 \%\end{array}$ & $\begin{array}{c}20 \\
11,7 \%\end{array}$ & $\begin{array}{c}29 \\
17 \%\end{array}$ & $\begin{array}{c}27 \\
15,8 \%\end{array}$ & $\begin{array}{c}24 \\
14 \%\end{array}$ & $\begin{array}{c}17 \\
9,9 \%\end{array}$ & $\begin{array}{c}11 \\
6,4 \%\end{array}$ \\
\hline Imagem $n^{\circ} 6$ & $\begin{array}{c}29 \\
17 \%\end{array}$ & $\begin{array}{c}19 \\
11,1 \%\end{array}$ & $\begin{array}{c}23 \\
13,5 \%\end{array}$ & $\begin{array}{c}29 \\
17 \%\end{array}$ & $\begin{array}{c}34 \\
19,9 \%\end{array}$ & $\begin{array}{c}24 \\
14 \%\end{array}$ & $\begin{array}{c}5 \\
2,9 \%\end{array}$ & $\begin{array}{c}5 \\
2,9 \%\end{array}$ & $\begin{array}{c}2 \\
1,2 \%\end{array}$ & $\begin{array}{c}1 \\
0,6 \%\end{array}$ \\
\hline Imagem $n^{\circ} 7$ & $\begin{array}{c}34 \\
19,9 \%\end{array}$ & $\begin{array}{c}18 \\
10,5 \%\end{array}$ & $\begin{array}{c}20 \\
11,7 \%\end{array}$ & $\begin{array}{c}20 \\
11,7 \%\end{array}$ & $\begin{array}{c}27 \\
15,8 \%\end{array}$ & $\begin{array}{c}18 \\
10,5 \%\end{array}$ & $\begin{array}{c}18 \\
10,5 \%\end{array}$ & $\begin{array}{c}9 \\
5,3 \%\end{array}$ & $\begin{array}{c}6 \\
3,5 \%\end{array}$ & $\begin{array}{c}1 \\
0,6 \%\end{array}$ \\
\hline Imagem $n^{\circ} 8$ & $\begin{array}{c}20 \\
11,7 \%\end{array}$ & $\begin{array}{c}8 \\
4,7 \%\end{array}$ & $\begin{array}{c}17 \\
9,9 \%\end{array}$ & $\begin{array}{c}26 \\
15,2 \%\end{array}$ & $\begin{array}{c}25 \\
14,6 \%\end{array}$ & $\begin{array}{c}27 \\
15,8 \%\end{array}$ & $\begin{array}{c}20 \\
11,7 \%\end{array}$ & $\begin{array}{c}17 \\
9,9 \%\end{array}$ & $\begin{array}{c}9 \\
5,3 \%\end{array}$ & $\begin{array}{c}2 \\
1,2 \%\end{array}$ \\
\hline Imagem $n^{\circ} 9$ & $\begin{array}{c}25 \\
14,6 \%\end{array}$ & $\begin{array}{c}20 \\
11,7 \%\end{array}$ & $\begin{array}{c}16 \\
9,4 \%\end{array}$ & $\begin{array}{c}30 \\
17,5 \%\end{array}$ & $\begin{array}{c}31 \\
18,1 \%\end{array}$ & $\begin{array}{c}23 \\
13,5 \%\end{array}$ & $\begin{array}{c}19 \\
11,1 \%\end{array}$ & $\begin{array}{c}4 \\
2,3 \%\end{array}$ & $\begin{array}{c}1 \\
0,6 \%\end{array}$ & $\begin{array}{c}2 \\
1,2 \%\end{array}$ \\
\hline
\end{tabular}

Fonte: Autores.

\section{Discussão}

O perfil socioeconômico dos entrevistados compõe majoritariamente mulheres, residentes na região Nordeste do Brasil, com ensino superior incompleto, da faixa etária de 25 a 31 anos, com renda familiar mensal de 3 a 6 salários mínimos, que utilizam as redes sociais digitais WhatsApp e Instagram em quase sua totalidade, por mais de 4 horas diárias.

A Hootsuite + We Are Social são "duas agências de marketing digital especializadas em mídias sociais com atuação no mundo inteiro" (Pareto, 2019). De acordo com o último relatório divulgado pelo Hootsuite + We Are Social, de 2019, o perfil socioeconômico das pessoas que fazem uso das mídias sociais compõe pessoas entre 18 e 44 anos, especialmente do sexo feminino. O brasileiro passa 9 horas 29 minutos por dia na internet, dessas sendo 4 horas 45 minutos na internet móvel. As redes sociais mais utilizadas foram Youtube (95\%), Facebook (90\%), WhatsApp (89\%) e Instagram (71\%). No que diz respeito à inserção elegível de cada rede social no Brasil (percentual de usuários na população acima de 13 anos), o estudo mostra que $75 \%$ da população brasileira está no Facebook e 40\% no Instagram. Números bem acima da média global de 35\% e de $15 \%$, respectivamente; os valores são baixos para a inserção do Snapchat (6\%) e do Twitter (5\%). Na presente pesquisa, 
verificou-se que as quatro redes sociais mais utilizadas em ordem de mais adesão para menor adesão foram: WhatsApp, Instagram, Youtube e Twitter.

Em relação à avaliação do sorriso pelos participantes da pesquisa observou-se que a maioria dos entrevistados considera a posição dos dentes algo de bastante valor, que estão felizes com seu atual sorriso, porém gostariam de modificar algo, sendo a cor dos dentes o mais citado. Consideram mais atrativos dentes compridos e largos, alinhados em seus arcos, com cor naturalmente claros. No estudo de Alves et al., (2014), encontrou-se resultado semelhante, onde 48,3\% dos seus entrevistados referiu-se a dentes alinhados como mais atrativo; 41,6\% consideram a cor dos dentes como algo de grande importância, porém $66,6 \%$ dos seus entrevistados relataram estar satisfeitos com seus próprios sorrisos, em contrapartida aos $17,5 \%$ encontrados no estudo atual.

De acordo com França (2010):

A seleção da cor do dente artificial é um processo determinante para a aceitação do tratamento pelo paciente. Os resultados da pesquisa apresentam como preferência entre alunos $(31,7 \%)$ e pacientes $(55 \%)$ os dentes artificiais da cor 1A, que representam os dentes mais claros da escala. [...]. Provavelmente, a grande influência que a mídia exerce sobre a opinião da população, exibindo sorrisos extremamente claros, interfere, muitas vezes, no padrão de beleza que é exigido pelos pacientes.

Comparando com os dados obtidos nesta pesquisa, o artigo de França (2010) aponta que os pacientes escolheram cor 1A da escala vitta, equivalendo ao mesmo padrão escolhido pela maioria no presente estudo. Salientando a fixação dos entrevistados pelos sorrisos mais brancos, Indusbello (2020) reforçou o termo "brancorexia", onde é a obsessão que as pessoas têm de possuírem dentes brancos. O sorriso perfeito e extremamente branco veiculado em excesso na mídia influencia as pessoas a desejarem esse sorriso irreal.

Conforme exposto no gráfico 1 quase metade dos entrevistados consideram que as mídias sociais digitais influenciam parcialmente nas respostas atribuídas ao questionário. Logo, a percepção do sorriso de modo geral é influenciada pela vivência dos entrevistados nas mídias sociais digitais. Guy Debord, em A sociedade do espetáculo diz:

o espetáculo apresenta-se ao mesmo tempo como a própria sociedade, como uma parte da sociedade e como instrumento de unificação. Como parte da sociedade, ele é expressamente o setor que concentra todo olhar e toda consciência. [...] a unificação que realiza é tão somente a linguagem oficial da separação generalizada. O espetáculo não é um conjunto de imagens, mas uma relação social entre pessoas, mediadas por imagens (Debord, 2000).

O gráfico 2 apresenta resultados de uma questão aberta, formulada aos participantes, onde o entrevistado deveria citar o nome de alguma pessoa popularmente conhecida no Brasil no momento que a pesquisa foi realizada associando ao sorriso. A cantora Anitta (Larissa de Machado Macedo); a atriz Bruna Marquezine; a influencer Boca Rosa e o influencer Whindersson Nunes Batista foram os mais citados.

Influencer, ou formadores de opinião são, segundo Lyons e Henderson (2005 apud Almeida, 2018), “indivíduos que fazem parte do grupo de adotantes imediatos no ciclo de vida de produtos, apresentam envolvimento duradouro com produtos ao longo do tempo e níveis elevados de capacidade de inovação, curiosidade e tendência à exploração". Dessa forma, o sorriso dessas pessoas é extremamente visado, e geralmente é compartilhado os tipos de tratamentos dentais que eles realizam, incitando o público a se interessar. De acordo com Barros, C. (2013), aquilo que é considerado belo é conhecido por todo o mundo e as reações, independente da localidade e cultura, são parecidas, logo, o conceito de belo pode até ter pequenas variações, mas de alguma forma convergem para um coeficiente global.

Como a pesquisa foi realizada no começo do isolamento social da pandemia do COVID-19, forçou o Brasil inteiro a isolar socialmente a população, modificando o cotidiano do país. Deduz-se que os entrevistados possuíam acesso à internet, e 
por isso, a citação da cantora Anitta é justificada, pois a mesma participava ativamente das mídias sociais digitais e mídias offline (Tv e rádio). A atriz Bruna Marquezine e a influencer Boca Rosa, ao momento da pesquisa, eram figuras com presença constante na TV em consequência do reality show BBB da TV Globo. O influencer Whindersson Nunes é um dos maiores criadores de conteúdo da plataforma Youtube brasileira, e também aparece constantemente nos programas televisivos.

O objetivo de o entrevistado citar o nome de alguma pessoa popularmente conhecida foi no intuito de notarmos quais pessoas são mais lembradas no imaginário popular, e ao serem citadas, essas pessoas provavelmente estão categorizadas como referencial em beleza e/ou estética e/ou admiração por qualquer outro motivo.

A Tabela 3 apresenta as avaliações atribuídas pelos participantes às nove imagens de sorriso que se encontram em anexo. Observa-se que a imagem número 7 apresentou piores notas, seguida da imagem 6. A imagem 7 faz referência a um rosto masculino com dentes brancos, largos e de aspecto artificial e a imagem 6 a um rosto feminino com dentes curtos. Esses dados corroboram com as avaliações individuais dos participantes em relação ao sorriso, expostos na Tabela 2 , onde dentes muito brancos e pequenos apresentaram os piores índices de aceitação. A imagem 1 foi a que recebeu maiores percentuais de nota máxima, seguidas das imagens 3 e 4.

A imagem 1 e 3 possuem em comum o fato duas influencers possuírem elementos dentários naturais sem a presença de lentes de contato dentais ou facetas, considerados de tamanhos compridos e largos, porém foram realizados procedimentos de clareamento dental em algum período de suas vidas. Já a imagem 4, referente a influencer Julia Petit possui preenchimento labial desarmonioso, onde não é possível observar suas papilas gengivais no ato de sorrir, podendo justificar o fato de ter recebido notas bastante variadas (9, 7 e 5 foram as notas mais altas atribuídas), predizendo a incerteza entre os entrevistados se o sorriso dela era satisfatório ou não entre eles.

Embora Whindersson Nunes tenha sido uma das 4 celebridades mais citadas pelos participantes, percebeu-se quando da avaliação do seu sorriso (figura 7 - tabela 4) que foi considerado como o de pior aceitação. Pode-se concluir que a associação da imagem de celebridade não necessariamente seria a imagem mais aceita, como padrão de beleza, pelos participantes. É um sorriso que desperta a atenção, no entanto não seria o mais aceito socialmente. O sorriso de Whindersson Nunes é composto por lentes de contato realizadas em 2015, ainda no início do boom dos procedimentos com lentes de contato dentais, e foi um procedimento bastante publicizado pois o resultado mostrou-se incongruente com a anatomia natural conhecida de cada dente.

De forma geral, mesmo que os sorrisos melhores avaliados no questionário possuam dentes compridos e largos, alinhados em seus arcos (todas as fotos apresentadas possuíam como característica em comum dentes alinhados em seus arcos), com coloração naturalmente claros, ainda assim poucos sorrisos conseguiram notas consideradas altas. As imagens utilizadas no questionário atendem majoritariamente a esses requisitos, porém mesmo os sorrisos demonstrados não foram considerados como padrão máximo de beleza. Então, qual o consenso para o sorriso perfeito?

\section{Conclusão}

Embora os entrevistados tenham afirmado que estão felizes com seus sorrisos, eles ainda desejam modificar algo. A percepção do sorriso, de um modo geral, é influenciada pela vivência dos entrevistados nas mídias sociais digitais. No âmbito da Odontologia, é essencial estudar como essa interação das mídias sociais digitais influencia nas escolhas dos pacientes, pois muitos virão ao consultório com ideias pré-definidas e estabelecidas pelo que viram na internet.

\section{Referências}

Almeida, M. I. S. et al (2018). Quem Lidera sua Opinião? Influência dos Formadores de Opinião Digitais no Engajamento. Revista de Administração Contemporânea, 22(1), 115-137. 
Research, Society and Development, v. 10, n. 6, e46810615727, 2021

(CC BY 4.0) | ISSN 2525-3409 | DOI: http://dx.doi.org/10.33448/rsd-v10i6.15727

Alves, G. N. \& Aras, W. M. F. (2014). Percepção de pacientes em relação a estética dentária. Revista SaúdeCom, 10(2), 161-171.

Alves, A. L. S. (2018). A influência da mídia na percepção da estética odontológica. Trabalho de Conclusão de Curso (Graduação em Odontologia). Universidade Federal de Santa Catarina.

Barros, C. D. (2013). A beleza e a feiura na contemporaneidade. Revista de Estudos Culturais e da Contemporaneidade, 73-86.

Carrera, F. (2012). Instagram No Facebook: Uma Reflexão Sobre Ethos, Consumo E Construção De Subjetividade Em Sites De Redes Sociais. Revista Interamericana de Comunicação Midiática, 11 (22), 148-165.

Cavalcanti, A. N., Azevedo, J. F. \& Mathias, P. (2017). Harmonização Orofacial: A Odontologia Além Do Sorriso. Revista Bahiana de Odontologia, 8(2), 3536.

Debord, G. (1967). A sociedade do espetáculo. (1 ed.). Contraponto.

França, P. V. B. R., Inoue, R. T., Bonachela, W. C., \& Salles, M. A. (2010). Análise comparativa da percepção estética entre estudantes de odontologia e seus pacientes em relação à seleção de cor e forma de dentes artificiais. Innovations Implant Journal, 5(3), 23-28.

Gimenez, F. (2016). A estética do sorriso. Trabalho de Conclusão de Curso (Graduação em Odontologia). Universidade Estadual de Londrina.

Hung, H. \& Yuen, S. C. (2010). Educational use of social networking technology in higher education. Teaching in Higher Education, 15: 6, 703 — 714.

Indusbello. (2020). Cuidado com a brancorexia: obsessão por dentes brancos. http://www.ib-indusbello.com.br/pt/post/67/cuidado-com-a-brancorexia:obsessao-por-dentes-brancos

Lakatos, E. M. \& Marconi, M. A. (2010). Fundamentos da metodologia científica. 7 ed. Atlas.

Lima, R. G. (2017). Publipost: a influência do instagram no comportamento da jovem consumidora. Trabalho de Conclusão de Curso (Graduação em Administração). Centro Universitário de Brasília.

Lins, B. F. E. (2013). A evolução da Internet: uma perspectiva histórica. Cadernos Aslegis, 48, 11-45.

Macedo, I. (2021). O Instagram como ferramenta de consumo de moda: uma análise do papel das líderes de opinião para o comportamento de compra das adolescentes. Tese (Mestrado em Administração). Universidade Federal de Pernambuco.

Pareto, A. (2019). Hootsuite + We are social $=O M G$. https://blog.pareto.io/publico-digital-hootsuite-we-aresocial/\#: :text=\%E2\%80\%9Chootsuite\%E2\%80\%9D\%20e\%20\%E2\%80\%9Cwe\%20are,para\%20\%C2\%BA\%20gestor\%20de\%20marketing.

Recuero, R. (2014). Redes sociais na internet. Porto Alegre, RS: Sulina. (Coleção Cibercultura) 2. ed. 206 p.

Ribeiro, V. (2015). Lentes de contato e uma análise de seus aspectos clínicos. Trabalho de Conclusão de Curso (Graduação em Odontologia). Universidade Tiradentes.

Rocha Neto, M., Barreto, L. K. S. \& Souza, L. A. (2016). As mídias sociais digitais como ferramentas de comunicação e marketing na contemporaneidade. Quipus, 4(2), 11-21.

Silva, A. S., Pinto, F. S., Silva, M. L. B. \& Teixeira, J. F. (2019). A Influência do Instagram no cotidiano: Possíveis Impactos do Aplicativo em seus usuários. Intercom - Sociedade Brasileira de Estudos Interdisciplinares da Comunicação.

Suenaga, C., Lisboa, D. C., Silva, M. S., \& Paula, V. B. (2012). Conceito, Beleza e contemporaneidade: fragmentos históricos no decorrer da evolução estética. Trabalho de conclusão de Curso (Cosmetologia e Estética), Universidade do Vale do Itajaí, Itajaí.

Vargas, E. G. A. (2014). A influência da mídia na construção da imagem corporal. Revista brasileira de nutrição clínica, 9(1), 73-75.,

Vieira, A. G. A. (2019). Instagram: Possíveis Influências na Construção dos Padrões Hegemônicos de Beleza Entre Mulheres Jovens. Trabalho de Conclusão de Curso (Graduação em Psicologia). Centro Universitário de Brasília. 